\title{
EARLY POSTOPERATIVE OUTCOME IN OPEN AND LAPAROSCOPIC APPENDECTOMY. OUR COMPARATIVE DATA ANALYSIS
}

\author{
Andrej Nikolovski, Shenol Tahir, Gjorgji Stavridis, Ali Devaja, Igor Fildisevski, \\ Dragoslav Mladenovic \\ University Surgery Clinic "Sv. Naum Ohridski”, Skopje, Macedonia
}

\begin{abstract}
INTRODUCTION: After the introduction of laparoscopic appendectomy (LA) in 1981, it is used as one of the operative methods in the treatment of acute appendicitis ever since. Some of the surgeons almost completely replaced open appendectomy $(\mathrm{OA})$ by its laparoscopic alternative, while others still have doubts about its universality. Early postoperative outcome has acceptable results when these two methods are compared, and that is the aim of this study.

PATIENTS AND METHODS: This retrospective study includes 798 patients operated for the diagnosis of acute appendicitis in period 2012 - 2016. Both OA and LA were made by four surgeons in 650 and 148 patients, respectively.

RESULTS: Intrahospital mortality in OA group was $0.3 \%$ ( 2 patients) and $0.6 \%$ in the LA group (1 patient). Early postoperative outcome was measured through the length of stay (5.1 for OA and 3.1 for LA), superficial surgical site infections $-4.7 \%$ in $\mathrm{OA}$ versus $2.7 \%$ in LA. Postoperative intraabdominal abscess occurred in $2 \%(\mathrm{OA})$ and $4.05 \%(\mathrm{OA})$. The conversion rate was $4.7 \%$.

CONCLUSION: Open appendectomy and LA are both used as two surgical alternatives in the treatment of acute appendicitis with comparable early postoperative outcomes. Although LA is almost 100 years younger as an operative method, $O A$ is still widely used. The choice of the procedure should be probably based on surgeon or patient preference. Scr Sci Med 2017; 49(3): 31-34
\end{abstract}

Keywords: open appendectomy, laparoscopic appendectomy, early postoperative outcome

Address for correspondence:

Andrej Petar Nikolovski

University Surgery Clinic "St. Naum Ohridski"

Skopje, Macedonia

e-mail:andrejnikolovski@ymail.com

Received: July 28, 2017

Accepted: September 15, 2017

\section{INTRODUCTION}

Open appendectomy $(\mathrm{OA})$ became the standard operative procedure after the muscle splitting incision described by Charles H. McBurney in 1894 (1). It was used as a gold standard method for acute appendicitis with or without modifications for almost a hundred years (2). The overall mortality of OA is $0.3 \%$, and the morbidity about $11 \%$ (3). Then, in 1983 the first laparoscopic appendectomy (LA) was per- 
formed by a German gynecologist, Kurt Semm (4). Contrary to the laparoscopic cholecystectomy that gained popularity and became gold standard for extraction of the gallbladder, there is still a lack of consensus about the most appropriate operative method for the acute appendicitis. In our clinic both OA and LA are performed. Only few surgeons that routinely perform LA offer to the patients to choose, while the rest mostly are using the open technique.

\section{PATIENTS AND METHODS}

This retrospective study analyzes 798 patients operated under preoperative diagnosis for acute appendicitis in the period of 5 years $(2012-2016)(\mathrm{Ta}-$ ble 1). Open appendectomy was performed in 650 and LA in 148 patients. Laparoscopic appendectomy was done by four surgeons. Patient age range was between 9 and 65 years. The diagnosis was established by proper anamnesis, physical examination, complete blood count with CRP and ultrasonography. A third generation cephalorsporine was given 1 hour prior to skin incision.

Table 1

\begin{tabular}{lc|c} 
Year & OA & LA \\
\hline 2012 & 131 & 17 \\
2013 & 125 & 23 \\
2014 & 118 & 38 \\
2015 & 148 & 28 \\
2016 & 128 & 42 \\
Total & 650 & 148 \\
\hline
\end{tabular}

Open appendectomy was performed with the standard muscle-splitting McBurney technique. The appendiceal stump and the appendicular artery were double ligated.

Laparoscopic appendectomy was performed with three-trocar technique. One $10 \mathrm{~mm}$ placed in supraumbillical position (camera), one $5 \mathrm{~mm}$ in suprapubic position (retractor) and one $10 \mathrm{~mm}$ in lower left quadrant (working). A zero-degree telescope was used. Bipolar sealing of the mesoappendix and the appendicular artery was provided by LigaSure AtlasTM $(10 \mathrm{~mm}, 37 \mathrm{~cm})$. The appendiceal stump was secured by ENDOLOOP ${ }^{\oplus}$ Ligature, Vicryl 0. Extraction of the appendix was done with endobag.
Use of drains in both techniques was not a routine and depended by the local finding.

All the patients over the age of 18 received Enoxaparin. The postoperative use of antibiotics was individualized regarding the intraoperative finding.

\section{RESULTS}

Intraoperative findings confirmed the preoperative diagnosis of acute appendicitis in 703 patients (88\%). The rest 95 patients (12\%) had other intraoperative findings. Positive findings were categorized in four groups: uncomplicated acute appendicitis, gangrenous appendicitis, appendiceal abscess and perforated appendicitis with generalized peritonitis. Two patients were operated with preoperative diagnosis for chronic appendicitis that was proven histologically. In the OA group positive finding for acute appendicitis was found in 582 patients, and normal appendix was found in 68 patients (10.4\%). Laparoscopic appendectomy group showed normal appendix in 25 patients (16.8\%) (Table 2).

Table 2

\begin{tabular}{lcc} 
Intraoperative findings & OA & LA \\
$\begin{array}{l}\text { Uncomplicated acute } \\
\text { appendicitis }\end{array}$ & 320 & 84 \\
$\begin{array}{l}\text { Appendiceal gangrene } \\
\text { Appendiceal abscess }\end{array}$ & 168 & 36 \\
$\begin{array}{l}\text { Perforated app. with } \\
\text { diffuse peritonitis }\end{array}$ & 45 & - \\
$\begin{array}{l}\text { Chronic appendicitis } \\
\text { Other findings }\end{array}$ & - & 2 \\
Total & $680.4 \%)$ & $25(16.8 \%)$ \\
\hline
\end{tabular}

Intrahospital mortality in the OA group was $0.3 \%$ ( 2 patients). Cause of death in one was massive pulmonary embolism, and in the other cardiac failure. Both had perforated appendicitis with diffuse peritonitis. Postoperative death in the LA group occurred in one patient $(0.6 \%)$. She suffered from postoperative mesenteric thrombosis and generalized intestinal gangrene with perforation of the terminal ileum. The postmortem analysis of genetic status for known pro-thrombotic mutations has revealed compound heterozygosity for $677 \mathrm{C}>\mathrm{T}$ and $1298 \mathrm{~A}>\mathrm{C}$ in MTHFR gene and heterozygosity for Factor V R2 
mutation. Duration of stay in the OA group was 5.1 days, and in the LA group 3.1 days. Superficial surgical site infections (cellulitis, purulence) occurred in 31 patients (4.7\%) in OA versus 4 patients $(2.7 \%)$ in the LA group. Postoperative intraabdominal abscess was seen in the open group in 13 patients (2\%), and in 6 patients in the LA group (4.05\%). Conversion into open procedure was performed in 7 patients (4.7\%) due to bleeding (2), inability to close perforated base of the appendix (3) and failure due to technical difficulties (2) (Table 3).

Table 3

\begin{tabular}{lcc} 
Analyzed parameter & OA & LA \\
$\begin{array}{l}\text { Superficial SSI } \\
\text { (cellulitis, purulence) }\end{array}$ & $31(4.7 \%)$ & $4(2.7 \%)$ \\
$\begin{array}{l}\text { Duration of stay (days) } \\
\begin{array}{l}\text { Postoperative intraab- } \\
\text { dominal abscess }\end{array}\end{array}$ & 5.1 & 3.1 \\
$\begin{array}{l}\text { Mortality } \\
\text { Conversion rate }\end{array}$ & $2(0.3 \%)$ & $1(0.6 \%)$ \\
\hline
\end{tabular}

\section{DISCUSSION}

Laparoscopic appendectomy was performed for the first time in our Clinic in 2003 by the pediatric surgeons. Since then, many years passed until the general surgeons started to perform this technique routinely and by that I mean only some of them. In the present it is still unrecognized by many surgeons as a reliable and safe alternative procedure for acute appendicitis. Our data shows that only $14.5 \%$ of patients with acute appendicitis are operated by laparoscopy in the past 5 years. Regardless of these data, it is shown that LA offers some benefits for the patients in terms of less postoperative pain, shorter length of stay, lower wound infection rate and earlier postoperative recovery (5-7) it is still not clear whether open appendectomy (OA. On the other hand, other data shows that both methods are comparable for complications, duration of stay and recovery time (8) with the objective of identifying randomized trials that compared single-incision with conventional laparoscopic appendectomy. Outcome measures included 30-day morbidity, abdominal abscess, wound infection, open conversion, reoperation, operative time, length of hospital stay, and postoperative pain. Fixed-effects and random-effects models were used to calculate combined overall effect sizes of pooled data. Data are presented as odds ratios or weighted mean differences with $95 \%$ confidence intervals (CIs. The operative time in LA is shown to be longer.

The formation of intraabdominal abscess after LA seems to be higher especially in cases of perforated appendicitis $(10,11)$. Therefore, it is shown that LA has no advantages over OA in terms of primary outcome measures and the only significant advantage was in quality of life scores at 2 weeks after the operation $(12,13)$.

Finally, according to the guidelines for laparoscopic appendectomy of the Society of American Gastrointestinal and Endoscopic Surgeons (SAGES) from 2009: The indications for appendectomy are identical whether performed laparoscopically or open. (level III, Grade A). In terms of uncomplicated appendicitis, laparoscopic appendectomy is a safe and effective method (level I, grade A). Laparoscopic appendectomy may be performed safely in patients with perforated appendicitis. (Level II, grade B) and is possibly the preferred approach (level III, grade C) (14).

\section{CONCLUSION}

Open appendectomy an LA are both used as two surgical alternatives in the treatment of acute appendicitis with comparable early postoperative outcomes. No matter LA is almost 100 years younger as an operative method, OA is still widely used. The choice of the procedure should be probably based on surgeon or patient preference.

\section{REFERENCES}

1. McBurney C. IV. The iincision made in the abdominal wall in cases of appendicitis, with a description of a new method of pperating. Ann Surg. 1894;20(1):38-43.

2. Addiss DG, Shaffer N, Fowler BS, Tauxe RV. The epidemiology of appendicitis and appendectomy in the United States. Am J Epidemiol. 1990;132(5):910-25.

3. Andert A, Alizai HP, Klink CD, Neitzke N, Fitzner C, Heidenhain C, et al. Risk factors for morbidity after appendectomy. Langenbecks Arch Surg. 2017 Jul 27; doi: 10.1007/s00423-017-1608-3. 
4. Semm K. Endoscopic appendectomy. Endoscopy. 1983;15(2):59-64.

5. Li X, Zhang J, Sang L, Zhang W, Chu Z, Li X, et al. Laparoscopic versus conventional appendectomy - a meta-analysis of randomized controlled trials. BMC Gastroenterol. 2010 Nov 3;10:129. doi: 10.1186/1471-230X-10-129.

6. Biondi A, Di Stefano C, Ferrara F, Bellia A, Vacante M, Piazza L. Laparoscopic versus open appendectomy: a retrospective cohort study assessing outcomes and cost-effectiveness. World J Emerg Surg. 2016 Aug 30;11(1):44. doi: 10.1186/ s13017-016-0102-5.7.

7. Horvath P, Lange J, Bachmann R, Struller F, Königsrainer A, Zdichavsky M. Comparison of clinical outcome of laparoscopic versus open appendectomy for complicated appendicitis. Surg Endosc. 2017;31(1):199-205. doi: 10.1007/s00464-016-4957-z.

8. Antoniou SA, Koch OO, Antoniou GA, Lasithiotakis K, Chalkiadakis GE, Pointner R, et al. Meta-analysis of randomized trials on single-incision laparoscopic versus conventional laparoscopic appendectomy. Am J Surg. 2014;207(4):613-22. doi: 10.1016/j.amjsurg.2013.07.045. 